\title{
Correction to: Association of Autism with Maternal Infections, Perinatal and Other Risk Factors: A Case-Control Study
}

Dikran Richard Guisso ${ }^{1}$. Fadi S. Saadeh ${ }^{1}$. Dahlia Saab ${ }^{2}$. Joud El Deek ${ }^{1} \cdot$ Sarah Chamseddine ${ }^{1}$. Hadi Abou-El-Hassan ${ }^{1} \cdot$ Ghidaa Majari $^{1} \cdot$ Rose-Mary Boustany ${ }^{2,3}$ (])

Published online: 15 February 2018

○) Springer Science+Business Media, LLC, part of Springer Nature 2018

\section{Correction to: \\ Journal of Autism and Developmental Disorders https://doi.org/10.1007/s10803-017-3449-x}

The original version of this article unfortunately contained a mistake. The family name of Hadi Abou El Hassan was incorrect. The correct name is Hadi Abou-El-Hassan.

The original article can be found online at https://doi.org/10.1007/ s10803-017-3449-x.

Rose-Mary Boustany

rb50@aub.edu.lb

1 Faculty of Medicine, American University of Beirut, Beirut, Lebanon

2 Department of Biochemistry and Molecular Genetics, American University of Beirut, Riad El Solh, P. O. Box 11-0236, Beirut 1107 2020, Lebanon

3 Department of Pediatrics and Adolescent Medicine, American University of Beirut, Beirut, Lebanon 